\title{
TEACHING HISTORY TEACHERS DURING COVID-19: CHARTING POEMS, PATHWAYS AND AGENCY
}

DOI: http://dx.doi.org/10.17159/2223-0386/2020/n24a3

\author{
Sarah Godsell \\ University of the Witwatersrand, Johannesburg, South Africa \\ Sarah.godsell@wits.ac.za \\ ORCID No.: 0000-0002-3431-2868
}

\section{Abstract}

In this article I argue that Emergency Remote Teaching (ERT) has necessitated and produced some transformative teaching methods, using the frameworks of Freire and hooks. However, I argue, that their methods are incongruous with this moment of online learning because of the 'invisibilisation' of the marginalised and vulnerable students, who can and do easily disappear into the void of online learning. This makes dialogic teaching (Freire) and teaching in community (hooks) impossible. I use examples of two undergraduate history and history method (teaching history) classes, specifically looking at the teaching methods and the assessment methods. I draw thematically on what the students produced in their assessments, analysing their texts (poems, creative essays, artistic submissions), looking at how they engaged with the assignment (method) and what emerged in the assignment, reading specifically for political engagement. In this discussion, I look at both the possibilities and the limitations of online teaching. Ultimately, I argue, that the limitations outweigh the possibilities of online teaching, and that there is a danger in claiming victories or even good teaching standards in this context. The danger is that the students who disappear are written out of the script of the University, and the promises (however precarious) that post-university life in South Africa offers. My argument here, using two specific courses as evidence, is thus a contradiction and a balance: for exploring this portal, and everything it offers, but pushing back vehemently against complete online migration because, in a country as unequal as South Africa, it is unethical, unjust, and anti-critical pedagogy.

Keywords: Pedagogy; Online teaching and learning; COVID-19; History teaching; Methodology; Assessment; Critical pedagogy; Poetry; Creative texts.

\section{Introduction}

The sudden and unexpected move to Emergency Remote Teaching (ERT) 
due to COVID-19 has been traumatic for lecturers and students. We are in unprecedented times, which require unprecedented measures for all of us. The context for this study is the University of the Witwatersrand, Johannesburg, South Africa, March-September 2020: Through the initial phases of lockdown, the hopes for a quick reprieve, and the slow settling into the realization that this would be, at least, the rest of the year. The physical, psychological, economic, and emotional toll taken on every person in higher education has been deep and dramatic. The toll on more vulnerable people has been worse. Students were evacuated from student accommodation with no idea they would not be back for months. These students left study materials, laptops, and winter clothes, in their rooms. They had their keys taken away. Lecturers trying to propose alternate plans (specifically around social pedagogy, with C-19 People's Coalition, and alternate term solutions proposed by the Black Academic Caucus $)^{1}$ were not heard. It was all hands-on deck to teach lecturers to teach, and students to learn online. The inequalities in South Africa were not ignored, with some institutions providing data, low-data options, devices, phone friendly options and, most of all support, to all of their students.

Often the only data we had to assess who was present in the courses and who was not were the numbers of students who submitted their online assessments. That provided tangible numbers: who is fulfilling the requirements for which course. The number of students against the number of submissions. Numbers. The two courses I am using for this study are both undergraduate courses in a Bachelor of Education, one is a history content course, and one is a methodology course. I was, initially, happy because the first course that I had an assignment in, history methodology, 38 out of 39 students submitted. In being happy about 38/39 submission rate in my first online assignment, I reflected on number 39. In a face-toface situation, I may or may not know the student, may or may not follow up with them, they may or may not follow up with me. But there is a physical space that they occupy, they are embodied, in presence or absence on campus. Online, they disappear. They are the number 39: no submission. Email: no reply. They are invisibilised. There is a politics here to who is seen or unseen, who is supported academically and emotionally, or left unsupported. In the other course I was teaching the number invisibilised

1 This documentation can be found on the Black Academic Caucus Twitter feed, and through the C-19 People's Alliance COVID Post School working group's document "Public Universities with a Public Conscience" . (Drafted through a national discussion in South Africa amongst concerned academics, April 2020, no date) 
was 20 out of 180 . Twenty students who did not check in, did not hand in, did not appear-who disappeared. The terms 'embodied' and 'invisibilised' can be read as opposite: the students' bodies (their embodied-ness) is invisibilised in a non-physical online space; however, the students are 'embodied' as numbers, the number replacing their physical body in the course.

In this paper, I elaborate on the methods of ERT which I employed to get through the initial COVID-19 shutdown period, and reflect on the functionality and outcomes of these. I will also reflect on the 'invisibilising' effect of online learning using some students' reflections as well as the absence of students from the course.

\section{Methodology}

My primary method in this paper will be reflections on my own teaching (Ashwin, 2015) drawing on students' responses (poems, creative texts, and art) as covered by ethics protocol H18/10/10. Reflective teaching, as I have used it, is a method that involves detailed note-taking and reflection on your own practices, in this case my teaching practices during the ERT. There are several aspects of my teaching that I will examine. First, my teaching practices online: using voice recordings and WhatsApp lessons, with the WhatsApp space also used as a support framework. The second will be my assessment practices: how these were adapted, changed, or remained the same, and the effectiveness of this. The third aspect I will draw on results from the assessment practices. I want to stress that this is qualitative research, and the data here are analysed thematically, rather than analysed around marks or student performance. This is because thematic analysis gives rich qualitative data, which I draw on for my conclusions. Thematic analysis allows for data to be organized around theme: educational engagement, political engagement, personal engagement. I will draw on three different aspects of what was submitted to me during as assessments. The first aspect on which I will reflect will be the answers to an essay question that was asked to the second years, in which they could respond in essay format or creatively (poetry was one example given). I will not be reflecting substantially on the substance of the responses, but on the way the students reacted or absorbed the materials taught during ERT. The second aspect I will examine is the "Decolonial History Teachers' Charter", which was part of an assessment in the $3^{\text {rd }}$ and $4^{\text {th }}$ year methodology class 
that I teach. The third and final aspect I will look at is the reflective exams which the methodology students wrote, which also gives an idea of the conditions under which students were studying, and how online teaching, and COVID-19 impacted the learning for these students.

\section{Information and context about the courses used in this article}

The two courses discussed in this article are "History Method III" and "Social Sciences II". The two courses offer some differences and because of this each course has very different cohorts of students, and thus requires drastically different methods and levels of engagement, and content.

"History Method III" (HM) is a methodology course on how to teach history. We investigate the Curriculum Assessment Policy Statement (CAPS) History curriculum but in regard to historical thinking, historical framing, and different strategies in teaching history. This course has 39 students. They are either third years who are taking history as their first major, or fourth years who are taking history as their sub-major. Either way, they have chosen history; they display an interest in the subject and the teaching of it, which makes it possible to delve much deeper into the more philosophical - and essential - aspects of teaching history. There is a strong focus on decolonisation in this course, where we explore the CAPS curriculum (and its shortcomings) from viewpoints of power, marginalisation, and whose narratives are told.

"Social Sciences II" (SS II), is a course of 161 students. It is a secondyear course and is split into two sections: history in the first half of the year and geography in the second half of the year. Thus, students who want to teach either history or geography need to do both social sciences I and II. History and geography are very different subjects, in fact, the combination of them up to grade 9 has been questioned (Ndlovu et al., 2018), but this is beyond the scope of this paper. What is definitely tangible in the lectures (although not in online teaching) is that many of these students have either no interest in, or an active dislike of history, as roughly half of the class want to become geography teachers. The inability to gauge student interest and engagement is a big flaw in online teaching: BBB (Big Blue Button) lectures allow students to join with headphones only, so they are not called on to participate. Chats get some traction, but it is rare that this involved over 10 students. The body language disappears, and this seriously hampers lecturers' ability to engage. SSII is also a content course, covering the History of the United States of America (from Columbus to Black Power) 
and so the focus is on actual historical narratives; the slippery nature of truth; the different interpretations and manipulations of history are all taught through the history of the United States.

I went into ERT teaching these courses - among others. There were two important differences in going online in these courses. The first was the numbers - HM is a relatively small course, where I could know each student personally. SS II is a large course where I only knew the students who regularly speak in class, but do not know every individual person in the group. The second big difference is the amount of time I had spent teaching them before the onset of ERT. With HM, I had already taught them from the beginning of the year. The students had been in a course with me before so they were familiar with my teaching style and so we had an established rapport, or a community of practice as a class before the ERT The SS II class is divided into modules, and a colleague had taught the previous module, so I only had one (tentatively two but this was already during the corona fear, so few students attended) lecture with this class before the lockdown and the beginning of ERT. Although I had had very little time with the SS II group, what was the saving grace was the fact that I had taught this same group in first year, and so they were familiar with both my teaching style and methods and I with them. Because of the differences between these groups, like age, discipline focus, class size and so forth, I had to approach the spin into online teaching in very different ways which will be detailed in the following section.

\section{Teaching during COVID-19}

When we unexpectedly closed down universities in March 2020 because of COVID-19, we stopped in the middle of the semester. Lecturers and students were all taken completely off guard. What followed were several surreal weeks of trying to get our heads around how we would and could hold $^{2}$ our students and continue knowledge practices in ways that were inclusive, effective, and safe. This feat felt impossible and indeed proved to be impossible. No matter what online lectures do, there is no getting away from that fact that there were several aspects that made ERT an impossible task for a percentage of our students. ERT leaves the most vulnerable students out. I have experienced this through multiple platforms in 2020. Everything discussed within this paper occurs with a caveat: it is not for

2 I use the verb 'to hold' to encompass a support that is both academic and emotional. Holding is a holistic supporting that is intended to assist to not fall apart. 
everybody. It did not, does not, will not work for everybody.

\section{Absence/Presence}

The university - and the internet - provided an overflow of information at the beginning of lockdown. There were various webinars for staff and students on how to use our Information Management System (IMS). Some of these both the students and I mastered (mostly the ones that were to do with submitting assignments), and some that were beyond me. It required intense engagement, intense internet access, and access to a functioning laptop. One of the things that has been revealing during the COVID-19 epidemic is the assumed identity of the staff on campus: this speaks to the inherent whiteness of the university space (where whiteness incorporates a certain type of being, with a certain type of resource access). It is assumed that staff all have access to laptops (it is impossible to perform lecturer duties on a smart phone) and Wi-Fi. This proved problematic for a large number of colleagues, and while the university did eventually provide assistance, it made the first few weeks of ERT very precarious for some lecturers and their classes.

The IMS used by our University is known as SAKAI, and has very useful, but previously under-utilised functions. SAKAI is one of the sites that was zero-rated by the cell phone companies fairly early on in the lockdown, meaning that students and staff can access the site without using any data. Teaching and learning, and various other groups and faculties, provided non-stop online assistance and information on how to most effectively use SAKAI for assessment, communication, administration, organisation, and effective pedagogy. This was presented in online webinars during which I was alternately fascinated or overwhelmed, and during which I frantically took notes or hopelessly wept. There was a terrible sense of loss mixed into this activity, alongside fear and anxiety. I mention these emotions because they become important in my methodology of online teaching: online needing to be a space of holding emotions, a space of reflexivity and resilience rather than just a space of delivering a disembodied script-like curriculum - which is what ERT threatens to be. The difficult questions are examined using curriculum theory: particularly the idea of a responsive curriculum (Griesel, 2004; Fomunyam \& Teferra, 2017), the idea of an epistemically diverse curriculum (Luckett, 2001). I attempt to assess the gains made for curriculum development in South African higher education by the imposition of the SAQA interim registration requirements and the 
outcomes-based method of curriculum design. I also note the gaps not addressed by the SAQA reforms and suggest that the SAQA reforms lay the HE curriculum open to the global trends of the instrumentalisation and marketisation of knowledge. I also address two other internal epistemological challenges to the HE curriculum, namely post-modernism and scientism. I then propose an epistemically diverse curriculum in which four ways of knowing and learning are developed for all HE curricula. These are the traditional cognitive learning of propositional knowledge; learning by doing for the application of disciplinary knowledge; learning experientially and fourthly developing epistemic cognition so as to be able to think reflexively and contextually about one's learning. I suggest that such a curriculum could address both the local and global dimensions of a higher education curriculum and hold a necessary balance between Mode 1 and 2 knowledge production. Furthermore, I believe that one of the central educational challenges currently facing HE practitioners is the integration of the various desirable generic skills into a traditionally content-based curriculum. I suggest that, if learners are introduced to all four ways of knowing and learning, these generic skills (both transferable and transferring skills, and a decolonised curriculum (Luckett, Morreira \& Baijnath, 2019).

\section{Teaching History Method}

The HM class was at once more and less challenging than the larger SS II class. There were some key principles I took from Freire and hooks, being collectivity and vulnerability (hooks, 1994) and dialogic teaching, praxis (reflection and action) (Freire, 1996). These are all practices that require an extensive and extended relationship with students. It is very hard to build this relationship online, so where these functioned, when they did, it was because of a strong foundation that we had built in the class. This is very important to note: we are not talking about a developed online curriculum here, but an emergency move to remote teaching, that is rooted in praxis and relationships developed face-to-face (Vally et al., 2020).

This class was very cohesive, involved, and enjoyed discussion. ${ }^{3}$ While I experimented with using forums on IMS, students did not often engage there. I also experimented with using Wiki - a tool for collaborative document creation. I had hoped that these collaborative spaces would be

3 This is based on feedback from the class. 
used to make notes on, which would in turn help with exams, but this also shows the gap between possibility, expectation, and reality. Many students opened up that during this period they became completely assessment driven, rather than doing work to learn for the sake of learning and becoming good teachers. Students being assessment driven is generally an issue in higher education, and one solution I have explored with this is learning-oriented assessment (Carless, 2015). This entails learning processes taking place during the task, rather than simply an assessment of learning where students regurgitate information in a "banking" type situation (Freire, 1996). Another principle I try to apply right the way through my curriculum design, pedagogy, and assessment is the concept of Constructive Alignment (CA), which will be explored below. Pedagogy and assessments are all aligned to Intended Learning Outcomes (ILOs), so there is continuous and contiguous back alignment between the teaching, learning, and assessment.

The Freirian concepts I use during this course are dialogic exploration, selfreflection, action, and more reflection (praxis) and ideas of humanisation as well as conscientisation (Freire, 1996). I use the idea of transformative education from both Mezirow and hooks (hooks, 1994; Mezirow \& Taylor, 2011), but particularly draw on hooks' concept of vulnerability, and truthtelling, as well as building a community in the classroom. These are my foundations in teaching practice, and what I aspire to and work towards every day. I attempted not to let go of this when COVID-19 hit - I detail this below. I especially attempted with this class to make a safe space to speak, to see and be seen, by me and by colleagues in these classes.

\section{Platforms}

At the same time as I was teaching these courses I was attending a course for a post-graduate diploma. I was both heartened and discouraged by the teaching methods used to hold us as a student group through COVID-19. This post-graduate diploma course took place on Microsoft Teams (MS Teams), where we could have a regular meeting space, hear each other's voices, and be present for the flipped classroom methodology applied in the course. We were able to be split into groups, into pairs, into different rooms, and we could engage with different teaching technologies during the class. The chat in MS Teams provided a channel that arguably is beyond what can be provided in a face-to-face class. However, while I was able to 
learn a lot about online strategies from this course, I was unable to apply them even in my HM III course which has only 39 students. This is because limited access to technology severely curtailed what I wanted to do in and with this class. We couldn't use MS teams because MS teams uses too much data, even though it can be accessed from a phone or a laptop. Some students had access to data only once the university had provided it, which was not in the first week of teaching. Some students live in areas with precarious network coverage, proving a deeper problem than data, and access to consistent electricity was also an issue. However, these were not the only problems: there was also the issue of access in terms of epistemic access and agency. This is where and why I switched to using WhatsApp. My experiences as a student and as a lecturer both shaped my experience of this period, a privilege I worked into my teaching and research. BBB is an e-meeting facility, a new platform that has performed well elsewhere (Chidambaram, 2020) which will soon be available in my university. This may provide easier access for synchronous learning with students.

\section{Where and how WhatsApp worked}

During the semester one lockdown period, we conducted synchronous learning sessions twice a week. These sessions were conducted via a WhatsApp group of which all of the students, except number 39, were part. We engaged in WhatsApp discussions of prescribed readings, using the readings as the primary engagement for a flipped classroom (Tucker, 2012; Gilboy, Heinerichs \& Pazzaglia, 2015). Although not all students were online during the classes, we regularly had engagements with around 15 students being online and around 10 participating in the class. This way we were able to practice dialogic education (Fisher, 2007; Alexander, 2018). However, dialogic education, according to Freire, goes deeper than whose voice is heard, but to whose knowledge is taken seriously, who is in what power relation in the situation. This is hard to address in a systematic kind of educational structure like a university, where the power is imbued in hierarchies of rank, as well as the traditional teacher/ student power differential. Where, in the IMS, the forum is created as a non-hierarchical space where opinions and thoughts can be posted equally from students and lectures this seemingly does not play out in practice. This could be for several reasons - students are hesitant to post their own thoughts and feelings on a university platform, or are not familiar enough with the forums to feel comfortable with the technology. This ties into a 
different discussion of how to get students and lecturers comfortable with technologies, but this is not the focus of my paper. One of my arguments is that WhatsApp works because many students are already on it - and have an experience agency on it. Where the world has been so deeply shaken by COVID-19, and everyday life looks so different and feels so uncertain, aspects where agency and continuity can be found are valuable, especially where it relates to learning.

WhatsApp is a chat program that is used throughout South Africa (and other countries throughout the world), that millions of people use daily to chat, to stay in touch, and in times of COVID-19, this is significant. It is easy to set up groups on WhatsApp, so it works for individual contact as well as group contact. I argue that the most important aspect of WhatsApp is that students are using it, and so have an element of agency in their processes. I tried to heighten that sense of agency by using two strategies that I draw mostly from hooks (2003). These two strategies are neither new nor radical. They come from the most basic senses of human interactions and of seeing each other. The first strategy is check-in; the second strategy is lecturer vulnerability. Checking in means just that: asking students how they are, opening the classroom space to their inner lives as well as to their academic lives, and the linking of the two. The difficulty with this strategy is that if you do not have a relationship with students, it is harder to open this up. Also, sometimes people are apt to respond superficially, and if it doesn't really surpass the superficial, then the exercise serves no purpose. Checking in is also important in terms of how the technology works: are the students stimulated, following, overwhelmed? This has been argued as a key aspect of online teaching (Chidambaram, 2020).

An example of this is a tutorial group I run that was set up purely online, with no physical contact with the students. In an introductory session I asked the student to say a few words about who they are, and even though I opened up with an expansive message about myself, their introductions were perfunctory at best. This also speaks to the atmosphere created in the greater class: whether the students see a value to social-emotional learning, collectivity and group learning and so participate, or whether they do not, and remain silent.

This leads again to the difference between online learning, emergency remote learning, and looking at students' motivations. Students are often assessed based on their motivation (Boud, 2000) the idea that assessment 
always has to do double duty is introduced". It appears as if ERT has just added to this, because assessments clearly indicate whether or not the student is passing. This put added importance on the assessments that are given, and it is important to reimagine these assessments, if possible, in a transformative and decolonised framing.

\section{Assessment}

The following discussion is about an assessment that spanned face to face and ERT, and I will examine both contexts in which this unfolded. The HM class is small enough for there to be active collective decision-making processes about curriculum and pedagogy. This is not unusual, and this aligns with Freire and hooks. However, this process is rarely extended to assessment, where the knowledge and power hierarchy is mostly asserted: the lecturer sets the assessments and marks them, the students complete the assessments and receive marks.

There is an argument to be made around decolonising assessment (Godsell, forthcoming), which involves exact processes of disrupting power hierarchies. However, here, the argument tends more toward Assessment as Learning, rather than Assessment of Learning. This is crucial during ERT because the students' main participation in the course is through completing assessments. If we are able to use and harness this fact, using assessment as learning, we can not only shift power dynamics, but we can also perhaps use assessments for more than the purpose of delineating how well a student has grasped aspects of the course. Below, I will outline several methods that I have used during the ERT period which have the potential to be used as learning, as transformative or decolonial learning, and which functioned during ERT. These methods are multi-modal, and provided a more inclusive learning and assessment experience for learners.

\section{The creative essay}

In SS II, working with the large class, I worked with audio-lectures of 20 minutes, accompanying this with PowerPoint slides. This may be one area where post-COVID-19 technology can supplement face-to-face lectures: audio lectures that can be accessed and re-accessed whenever students need to. This allows information to be more easily absorbed. However, the phrase "easily absorbed" is also a problem. Many students gave feedback to this effect: while the audio-lectures are helpful and effective for conveying 
information they do not have the impact of a face-to-face lecture. This was because none of the important, controversial topics could be discussed, codified, and explored in a dialogic way in a large class with divergent opinions. Active learning is downgraded to passive learning. Because key concepts of the class were racial oppression, modes of resistance, colonisation, belonging, and land-ownership - all salient and fiery topics in South Africa in 2020 - this course needed classroom dialogue, and time and space. The key aspect of this course - as explained above - is that it was interrupted by the initial lockdown. Thus, the assessment option had already been chosen, which I adapted. The question was "Who does the country known as the United States of America belong to in 2020?" The space I gave in answering the question was that the students could answer in essay format or in any other creative format (such as poetry, as was used in the lectures) as long as it was accompanied by an argument statement, explaining the argument - which should be evident in the creative piece. The space for this kind of expression in answering a question is argued elsewhere.

\section{Example of outcome:}

Welcome to the United States of America

Or should I say

Welcome to America?

Well Welcome to America

Welcome to the country that belongs to the rich and powerful

Welcome to the wealthy land of every beings dream

Welcome to being an American for just a split second

They say America belongs to all who live in it

They say America's land belongs to those who fought for it

They say America is for all

They say being an American has no race or culture

They say to be an American is not to be born in America,

Not to be raised in

They say it is for all because all lives matter

Welcome to America

Flipping through thick books of history.

My eyes blurry with unshed tears.

With a lump clogging my throat.

And a heavy heart

As it dawns on me that it's all a dream, 
it's been a dream, and continues to be a dream

One dream, is all the slaves wanted

Freedom, integration, equal rights, justice and unity.

What a high price was paid for it

They had to be shadows

Shadows on the sidewalk

In the above poem the student engages key concepts of belonging, race, and critically engages history and present geographical norms by asking "What is America". This is an excerpt of a poem, and the whole poem contained more complex arguments. This excerpt however shows sufficient historical engagement but also shows a personal engagement poignantly engaging the dream of freedom that this student had been sold about "America".

\section{The decolonial history teachers charter}

The idea for a decolonial history teachers' charter initially came from the students themselves, during the face-to-face lectures in the beginning of the year. One student asked if they could draw up this kind of document. This happened in a particular context of focus on decolonisation and action. In the first lesson of our HM class, we went around the room to discuss what decolonisation meant to each student: although there were a variety of answers, the foundation of the thinking was around justice and transformative change. These concepts formed the grounding of our work in the history classroom. Then we did the work of tying the ideas about colonisation to ideas about history. It is important in this that the method was Freirian - that we followed prior knowledge and ideas, dialogic teaching, that tied in with theoretical approaches to decolonisation of various scholars. I did not teach decolonisation as a body of knowledge outside of the students, but rather as a body of ideas familiar to them, tied to the writings of many scholars. In linking decolonisation to history, the foundational ideas were "whose history", "from whose perspective" and "where does the power sit".

Linking decolonisation to history triggered key questions about voice and power. The class was enthusiastic about this way of thinking and transforming history from the dead subject they had often learnt at school to one that was not only alive in their everyday lives, but that was alive in their desired future too. 
While our classes were conducted in a dialogic way, the assignments set were set by me, as learning as assessment principles, and in line with principles of Constructive Alignment (Biggs, 2014)it is only recently that it has been implemented on a reasonably large scale. Part of the reason for this is that the massive expansion in tertiary education involves a diverse range of students and of teaching subjects so that teaching and assessment need to be reviewed on an institution-wide basis with emphasis upon outcomes at institutional, programme and unit levels. CA provides a framework for adjusting teaching and assessment to address the attainment of those outcomes and the standards reached. Research indicates that CA is effective in this but it initially requires time and effort in designing teaching and assessment and, as a systems approach, it is important that supporting institutional policies and procedures are in place. CA properly implemented enhances teaching and learning quality and thus, as a form of quality enhancement, subsumes forms of quality assurance that can often be counter-productive" (Biggs, 2014). As much as this incorporates students it does not disrupt the power hierarchies in the classroom or insert dialogic method into assessment methods.

One student in the class suggested that as a class project they collectively write a "decolonial historians charter". It is important that the suggestion came from a student and was widely accepted with excitement by the class. I split the class into groups and at the end of every lesson we spent 15 minutes working on the decolonial history teachers' charter. Their end goal for this is to come up with a document that can be shared widely by history teachers and can give directly and a mandate for radical pedagogical work in the history classroom.

Their work was guided by questions arising both from the class and from me. I brought in copies of the Freedom Charter as an example of what a charter could (not should) look like, and we discussed the progress made in the class. The progress was not linear or simple; the task was unclear and the end product was vague. This was important. In striving to make so much of the work we do in class clear and epistemically just, it is often possible to lose the value of opacity: when it is unclear what will be uncovered, when the answer is not already in a memo.

Some students thrived on this, some found it frustrating While the discussions continued students became more and more embroiled in what a decolonial charter might look like. 
Then COVID-19 happened. Classes were cancelled for a week, then two weeks. The university refused to call the closure a shut down - it was an early Easter vacation. Then meetings of over 100 people were banned, then over 50 people. Opening University again seemed to become more and more unlikely. The university began speaking about moving online, then to develop a plan for ERT.

As we moved online, we moved onto a WhatsApp group that had 38 of the 39 students in the class. I communicated with the $39^{\text {th }}$ via email, sporadically. I have discussed WhatsApp as a platform above. As we slowly came together as a class again, established time frames, readings, modes of meaning, we began to form an online social presence as a class. We discussed assessments - the dates had been pushed back, but the need for marks, the need for assessments, the need to consolidate the work we had done in semester one did not go away. However, my challenge was to align the formalised assessment with the formalised curriculum, while our discussion of decolonisation had been running alongside this, almost as a separate curriculum, more in an informal sphere. This is a fault in my curriculum planning and pedagogy, and one that I explore in a paper on "Decolonising Assessment" (Godsell, forthcoming). It questions how completely we may shift power structures if we are only able to shift up to assessment and not decolonise assessment itself.

I was ready to let go of the Decolonial Teachers' Charter and expected most students to give up on it also. However, when we were discussing assessments, with the awareness that this was during the first lockdown and many students were struggling physically and psychologically. I wanted to rethink their assessments for social pedagogical learning, in a way that could support them in a group collectively, while still meeting the assessment standards of reliability and validity, and each assessment having appropriate rigour. However, the world was upside down - we were all gripped with fear of what was coming, economically and physically. How to create a safe, valid, reliable assessment under COVID-19 conditions? I argue that this is impossible. For the reason elucidated above I argue that any assessment will be unjust, and so not form part of a radical pedagogy. Below, I describe what did happen, and how although it still forms part of a flawed moment and system, it makes some moves towards social pedagogy and towards radical and critical pedagogy. Social pedagogy is defined, by the C-19 Post-School Education Working Group as: 
... consultative, inclusive, and sensitive to the contexts of students, teachers and their communities. It works towards mutually supportive framework that will carry our pedagogic work through the current crisis, into a period of just recovery, and a more equitable future.

- We are guided by four principles:

Inclusivity and participation

"Equity and Equality

» Transformation and decolonisation

» Academic development and progress with integrity

(Drafted through a national discussion in South Africa amongst concerned academics, April 2020, p. 1).

The Decolonial Teachers' Charter as an assessment came up organically during a discussion of the types of assessment that could work online. The students had already had work due. Some had started and completed that work, and submitted it while others had yet to start. I am adding this point because I want to stress that the process is messy, incomplete, and not as smooth as University spokespersons will undoubtedly say in years to come. Others were struggling to keep up in the online environment, because of devices and connections, because of data and network, because of spaces and chores, because of the paralyzing fear of the pandemic. Also, we discussed what we would do about the process of the Decolonial History Teachers' charter. I had assumed that, being overwhelmed with work, they would want to drop the idea, but they did not. This was something of value to them that they felt important and worthwhile to pursue outside of the standard curricula and outside of assessment structures that they would need to write to obtain their degrees or to proceed to the next year. I was struck by this and drawn by decolonisation around whose voices are heard in a curriculum who is recognised as human.

This puts me in conflict with schools of thought where semantic density (the number of concepts attached to certain knowledge) is privileged over semantic gravity (how contextual the knowledge is) (Maton, 2014). However, the balance between different types of knowledge needs to be achieved to overcome the coloniality of knowledge (drawn from the enlightenment: "objective" and "rational" explicitly, white and male implicitly). The PCK (pedagogical content knowledge - Shulman, 1981) is obviously important. The d-PCK (disciplinary specific Pedagogical content knowledge) more so. I am not arguing that all knowledge in the classroom comes only from the students that other sources, including the lecturer, are constantly and 
critically brought into the classroom - but in allowing students a say in curricula shifts the power dynamics in the classroom.

As part of the consistent effort to move these power dynamics towards decolonisation, I asked the students if they would like to do the Decolonial History Teachers' Charter as an assessment. After some discussion we came to the following agreement:

- Students could choose whether they wanted to do the assessment that had been designed before COVID-19 or the Decolonial History Teachers' Charter.

- Those choosing the Decolonial History Teachers' charter would agree that this was a collective effort, and each person participating would get the same mark. I would not entertain complaints about some people not having worked enough: embarking on this project was a collective choice.

- They would work among themselves, that I would give no guidance towards the charter, recognising it as their coursework assignment.

- I would design a rubric which we would collectively adjust until it was agreed on by the class. This would provide clarity for both parties as this was for marks.

These agreements were important for several reasons: to ensure that participating in a different assessment process was the student's choice; to ensure that, in line with decolonial principles, this was a collective project, with a radical political understanding of collective - where the stronger also support the more vulnerable. Thirdly that this rather different assessment project would have a valid and reliable marking structure, and that that was co-designed by lecture and students. This again links to ideas of shifting power-dynamics towards decolonising assessment (see Godsell; forthcoming).

We then decided on the form and format in which the students would work: there is a collaborative document tool on our IMS which allows anonymous editing, and collaborative writing. I had put some of the notes that I had had from our class discussions and exercises on the Decolonial History Teachers' Charter, hoping to kick off a collaborative process for the charter before we decided to make it an assessment. I want to pause here and reflect on our students' apparently being primarily driven by marks, which was seemingly exacerbated, as I have mentioned, by ERT. Biggs (2011) designed an idea of 3 levels of teacher expertise: the first level is "blame the student", the second is "blame the teacher" and the third level, 
the one teachers should (according to Biggs), aspire to, involves focusing on looking at what students "do" - which involves looking at the various teaching and learning contexts of the class, the teacher, and the student. The first two levels involve deficit models, and we often tend to apply a deficit model of the students (Biggs, 2011), or a deficit model of ourselves as teachers, rather than focus on what the student does. In this context, the students ended up doing collaborative learning; but if we were starting off with a deficit model, we might say they were not learning for learning's sake but only because we are driven by marks.

Lecturers express this with great distress. However, if we use this just as a fact contextually to ERT and perhaps even online teaching, we can add that fact to our course designs and use Constructive Alignment (Biggs, 2014) to make sure we use the facts of the context, and to use assessment as learning, or Learning-Oriented Assessment, to make sure our assessments produce rather than measure learning (Carless, 2015). In other words, use the marks-oriented students to do both marked formative and learning oriented summative development.

The Charter became a collaborative piece of assessment work, that would provide some gentleness for those that struggled with the ERT situation, as there was no stipulation as to how much someone must contribute to be eligible for a mark. This might also be seen as a significant weakness of the project. While each student had needed to report to me whether they would be doing the chart or the rubric and unit design, and this gave me some idea of who was active in the class (38/39) and measured their intentionality with the project, it could be argued that the assessment is not reliable, as it does not necessarily test the individual input of each student. I would argue that every groupwork project allows for such eventualities, and as much as we can built in checks and counterbalances (peer assessment forms, selfassessment forms, group presentations) we are asking a fundamentally different thing when we are asking for groupwork, as opposed to individual work: we are asking for collectivity. I would argue that the assessment is reliable because it can be performed over and over with similar results, and that it is valid because it draws both on the methodology we use in class, the contemporary socio-political contexts in which we live, and the decolonial politics of collectivity over individuality. The following extract displays the politics of the Charter: 


\section{Preface}

Until the lions have their own historians, the history of the hunt will always glorify the hunter (Chinua Achebe)

We, as student-teachers of History, recognize that our world finds itself at an unprecedented moment in human history. As we attempt to come to terms with the implications of the Coronavirus pandemic for the future of education on a global, continental and local scale, we recognize that we've been presented with an opportunity to critically re-imagine the role that Historians ought to be playing in actively building a more just, empathetic and equitable world. We deliberately identify ourselves as Historians-inaction, based on our understanding of History as a discipline that involves the active construction, deconstruction and contestation of historical narratives.

We have a duty to decolonise the history curriculum and have history become a tool for the nurturing of agency i.e. our capacity as human beings to reflect critically on the historical conditions that have affected our experiences and to act decisively upon these reflections. In order to be historians-in-action, we need to expose and shed light on African perspectives of colonization and its effects, as we have presently observed that such perspectives have limited place in dominant historical narratives. Our teaching and learning of history tends to glorify Eurocentric actions and perspectives. These perspectives prevail in much of what has been written in our history textbooks. And it is that history that we continue to teach and learn today. We have subscribed to the 'single story' for too long - an interpretation of history that has done little to disrupt unjust relations of power that continue to reproduce patterns of oppression, exploitation and domination in our society.

If we are to move forward on the basis of a more transformative conception of education; an education system that is rooted in the desire to empower and uplift our societies on a global, continental and local scale, then we need to dedicate ourselves to learning our true history and uncovering the truth of who we are. We recognize that this is a process that necessitates a critical acknowledgement of our strengths and our weaknesses. It is a process that requires us to take full advantage of the resources, skills and opportunities that we have at our disposal in order to make tomorrow better for ourselves and for future generations."

\section{The reflective exam}

Naidoo (2020) points out that unless the teaching is rooted in wanting a fundamental change of unjust systems, then the methods cannot be claimed as either Freirian or hooksian. This is then when the attempted transformative or radical methods I have attempted fall short: they fit within the system of ERT, even while the exam equivalent requires both objective and subjective 
viewpoints on the world in which COVID-19 is operating, the world in which these students are becoming teachers. "Objective" is also, of course, subjective, as we cannot ever delink ourselves from the context.

Much of being a history teacher is being aware of context, and being able to link context to historical knowledge, to avoid a banking education situation, or a dry, disconnected teaching from the textbook. Indeed, from a radical pedagogy or Freirian point of view, using this to actively bring about change in the world. Adopting a social pedagogy, one developed and practiced in community, the exam set for the third-year HM students was a reflexive examination entitled "looking out, looking in". This exam asked students to be reflective on their interior and exterior experiences during COVID-19, and link this to being history teachers, and history teaching.

This examination produced beautiful and thought-provoking answers, where students wove webs back and forth in time, around their environments, and historicised their past and present observations. Analysed thematically, the most consistent reflection was on the inequality in the country, and in the class, this was observed and from all angles of those with and those without. This was almost completely consistently followed by a historicization that linked currently equality to colonisation and apartheid creating racialised inequality. In dialogic teaching this moment of reflection - what the historical inequality had caused in the present, and your place in the systemic oppression - is the ideal reflection part of praxis. The way that this was presented varied, some in poetry, some in visual art, mostly in words but all answers showing historical reflection. This could work as a radical pedagogy when it is intended to conscientise and provide critical reflection with the act of reading (the world and the word) and writing (the world and the word) (Freire, 1983). There was a crucial point in each of the 6 responses selected for analysis where this codification and decodication - the reflection in praxis - took place.

Below is a particularly poignant example of an exam response by a student, Aasif Bulbulia.

\section{Looking out, looking in}

Instrumental used: Mos Def - Respiration (https://www.youtube.com/ watch? $=$ fHHSpfssBco)

Bismillah (In the name of Allah) 
$i$.

[0:24] looking out, looking in

where do I begin?

feel like a matador trapped in a bullpen

under lockdown, frozen like a mannequin

we get knocked down, gotta get back up again

so i take a moment to reflect

look at all the systems of oppression intersect

the anxiety is crippling, i gotta take a breath

start to see privilege as a matter of life and death

a product of inequality

they wanna surf while the people live in poverty

"kill the blacks for the sake of the economy"

so self-centred, they got a complex like Ptolemy ${ }^{4}$

the world crashed like a plane over Lockerbie

calculate the aftermath

someone call the cavalry

someone bring the body bags

come comfort the families

now more than ever, we need solidarity

I say that,

but that word can be quite abstract

easy to talk when you can always go back

to warm beds and full bellies

turn on the telly,

police and politicians acting like

Machiavelli

I told the man in the mirror,

"you gotta listen here

you gotta face your fear

of being insincere

you gotta start

by taking care of your heart

if you don't

just watch things fall apart

4 Ptolemy was a proponent of geocentric theory, which posited that the earth was the center of the universe (Jones, 2000). 
The above, the argument in the whole rap (accompanied by a beautiful beat) is to be brave, a call to action "You gotta face your fear of being insincere you gotta start by taking care of your heart if you don't just watch things fall apart", a call to face the fear, a call to radical self-care in order to take part in radical care of others and the world. This is one particular example, and this student is an activist. Not all students had this sense of purpose and urgency.

I have found that through important campaigns like Black Lives Matter, Stop Gender Based Violence, and the movement through private schools, questioning which systems are in place to encourage some leaners and silence others, have taught me very important lessons for being a teacher. My privilege is always going to be a hinderance for me, and I will be more privileged than many of my learners, so I need to learn to see beyond my blinkers. To teach with compassion and fairness. I do not want to become a part of the systematic racism that so many of my teachers were a part of. I will continue to check my privilege and will strive to be the teacher so many of my peers needed in high school. I cannot change the past, but I can learn from it to improve the future (Chelsey Mattuizzo, 2020).

The above extract - taken from Chelsey Mattuizzo's exam, shows the connection between being a teacher, a historian, and her own positionality. The extract shows reflection of what we had learnt in class: positionality, power in schools, historic systemic racism, and how we as teachers need to learn to be open to listening to what we do not know about.

These might be taken as an example that this online teaching worked the students did exceptionally well in their assignments, integrated knower gazes into their familiar gazes onto their world and transposed a trained historical gaze onto their situations, the local, and global situations, and how this might impact their classroom. This is valuable history method for future history teachers. However, there is student number 39. Some people might say this is acceptable collateral damage - that there will always be some students who drop out during the year. I refuse this argument and this academic violence. Every student counts. Every student matters. And yes, there will be drop-outs - but we cannot claim as radical a method which is not available to the most vulnerable, which cuts out students because of the modalities of the pedagogy.

\section{Conclusion}

We are in a time of transition - as Arundhati Roy famously said, "a portal" (Roy, 2020). We have opportunities to be together while far apart - for some. We have opportunities to use multiple modalities - some of 
us. While students are not in residences that at least provide a modicum of stability of food, of device connection, of network connection, we cannot teach online in South Africa without deepening a digital divide that strikes the deepest most tender fractures in our country. It puts us in a terrible position in 2020. Where do we go? What do we do? What do we not? There have been calls for "bad teaching", to not make lecturers disposable and also to not make an impression that we can seamlessly transition to ERT and then to Online Teaching and maintain the illusion of university as a pathway out of poverty, or even a functioning cog in a neoliberal capitalist machine. The act of transitioning online tells student 39 they do not exist in a meaningful enough way for us to care about them.

This article might seem contradictory. I have detailed how I have fought for my students, and with myself, and with society and the University during COVID-19. I have detailed the methods I have used, some which work and some which didn't. I have done this because I want to share methods tending towards social pedagogy that could work and help in an ERT situation, and because I am a historian and think it is important to document work done. This special issue is a nod towards that as well. Yet, I end with an invective against online teaching, removing any face to face time. I argue for a future of a University I want to be part of, that uses technology paired with face to face dialogic, decolonized and creative pedagogies and curricula to teach our students in all of their human, student, teacher, scholar, and intellectual, and bud of hope, beings. I argue that good pedagogies need to be thought through and not rushed - that ERT was the option chosen by our institutions (not the only option) was an option we did our best with. This article is a selection of my best and worst. And an invocation towards an intersectional pedagogy that sees our students, and fights with them for social justice.

\section{References}

Alexander, R 2018. Developing dialogic teaching: Genesis, process, trial, Research Papers in Education, 33(5):561-598.

Ashwin, P (ed.) 2015. Reflective teaching in higher education. London: Bloomsbury Academic (Reflective Teaching).

Biggs, J 2014. Constructive alignment in university teaching, HERDSA Review of Education, 1:5-22.

Biggs, JB 2011. Teaching for quality learning at university: What the student does. McGraw-Hill education (UK). 
Boud, D 2000. Sustainable assessment: Rethinking assessment for the learning society, Studies in Continuing Education, 22(2):151-167.

Carless, D 2015. Exploring learning-oriented sssessment processes, Higher Education: The International Journal of Higher Education Research, 69(6):963-976.

Chidambaram, SMDN 2020. Success of online teaching and learning in higher educationCOVID-19 pandemic: A case study, Valley View University, Ghana, International Journal of Applied Engineering Research, 15(7):735-738.

Drafted through a national discussion in South Africa amongst concerned academics, April 2020. Public universities with a public conscience: A proposed plan for a social pedagogy alternative in the time of pandemic. Available at: https://bit.ly/ public-education-plan-endorsement. Accessed: 15 September 2020.

Fisher, R 2007. Dialogic teaching: Developing thinking and metacognition through philosophical discussion, Early Child Development and Care, 177(6-7):615-631.

Fomunyam, KG and Teferra, D 2017. Curriculum responsiveness within the context of decolonisation in South African higher education, Perspectives in Education, 35(2): 196-207.

Freire, P 1983. The importance of the act of reading, Journal of education, 165(1):5-11.

Freire, P 1996. Pedagogy of the oppressed. London: Penguin Group.

Gilboy, MB, Heinerichs, S and Pazzaglia, G 2015. Enhancing student engagement using the flipped classroom, Journal of nutrition education and behavior, 47(1):109-114.

Griesel, H 2004. Curriculum responsiveness: Case studies in higher education. South African Universities Vice-Chancellors Association.

hooks, b 1994. Teaching to transgress: Education as the practice of freedom. New York: Routledge.

Luckett, K 2001. A proposal for an epistemically diverse curriculum for South African higher education in the 21st century, South African Journal of Higher Education, 15(2):49-61.

Luckett, K, Morreira, S and Baijnath, M 2019. Decolonizing the curriculum: Recontextualization, identity and self-critique in a post-apartheid university, Reimagining curriculum: Spaces for disruption. Stellenbosch: African Sun Media.

Mezirow, J \& Taylor, EW 2011. Transformative learning in practice: Insights from community, workplace, and higher education. Hoboken: John Wiley \& Sons.

Ndlovu, SM et al. 2018. Report of the History Ministerial Task Team for the Department of Basic Education. Pretoria, South Africa: Department of Basic Education, p. 156.

Roy, A 2020. Arundhati Roy: 'The pandemic is a portal' | Free to read. Available at: https://www.ft.com/content/10d8f5e8-74eb-11ea-95fe-fcd274e920ca. Accessed on 2 November 2020.

Tucker, B 2012. The flipped classroom, Education next, 12(1):82-83.

Vally, Z et al. 2020. Education researchers respond to The COVID-19 Pandemic RESEARCH REPORT. 